\title{
Psychological Aspects and Results of Innovative Thinking of a Manager
}

\section{Dilorom Daniyarovna Ergasheva}

Department of Innovative Education, Tashkent State University of Economics, Tashkent, Uzbekistan, dilorrome@gmail.com

\section{Gulbakhor Sattarovna Abdullakhanova}

Department of Social-humanitarian sciences, Tashkent State University of Economics, Tashkent, Uzbekistan,gulbakhor@yandex.ru

\section{Nargis Abdukhalilovna Alimatova}

Department of Social-humanitarian sciences, Tashkent State University of Economics, Tashkent, Uzbekistan,nargis221968@gmail.com

\section{Nilufar Sadullaevna Faizullaeva}

Department of Innovative Education, Tashkent State University of Economics, Tashkent, Uzbekistan, nilufarfs@yahoo.com

\section{Olga Ivanovna Stepanova}

Department of philosophy and logic, National University of Uzbekistan named after Mirzo Ulugbek, olgast1961@gmail.com

\section{ABSTRACT}

New types of thinking, studied and developed in recent decades, include such as innovative, managerial, strategic, critical and systemic as the highest level of thinking that synthesizes all types. Innovative thinking cannot be based on traditional logic. The innovative thinking of a leader, combined with managerial abilities, leads to personal progress of the manager himself, in the organization - to the emergence of a new product, thereby taking the company not only to a new level, but also to a leader.

Keywords: innovative intelligence, practical intelligence, logic, creative thinking, leadership style.

\section{Introduction}

At the present stage, in any state of the world, one of the important requirements are to ensure the innovative nature of the development of education, economy, industry, and in general all spheres of society. Psychological characteristics, personal potential, abilities that determine the success of innovation, the development and implementation of innovations, the creative nature of thinking and activity are decisive in this.
These circumstances determine the relevance of the development of modern approaches to understanding the factors of the success of creative, innovative activity, its productivity and highlighting as the most important such factor a special personality characteristic - innovative intelligence.

The current stage of development of the Republic of Uzbekistan, socio-economic transformations require the promotion of 
managers of a new type - confident, capable of creative problem solving, purposeful, enterprising, proactive, thinking, decisive, able to work effectively in an environment of changing conditions.

Integrating into the world community, our country realizes that in the modern world high technologies are the basis of competitiveness. For this reason, the transition to innovative development and innovative thinking are absolutely necessary for the Republic of Uzbekistan. Innovative thinking is becoming meaningful and in demand. Nevertheless, few people are capable of innovative thinking and creating new technologies. The problem of forming people capable of effectively managing in the context of an innovative environment in the current economic and social conditions is long overdue.

A number of companies on the brink of bankruptcy suddenly turned into market leaders thanks to the efforts of effective managers capable of change and innovative breakthrough. These leaders used different types of thinking, knew how to combine them into a single whole, and systematically solve complex problems. Those managers who are aware of the need for changes, changes in approaches to the management of innovative activities, who are capable and ready for risk and instability, win and become world leaders. And, of course, they understand the high importance of the role of the organization's personnel, develop their creative abilities in every possible way, expand their professional horizons, motivate them to new technological achievements, demonstrating new approaches to managing all activities and personnel management.

Thus, a sustainable and practically unlimited source of new growth for any organization is the innovative thinking of a manager, which looks like a search for new ways to solve problems, the ability to accentuate, isolate a problem, generally improve its structure based on unconventional ideas and implement them, cultivating an innovative climate in their organization.

\section{METHODS AND MATERIALS}

in the presented work, we used an analysis of the methodological foundations of the professional activities of managers, generalization of managerial experience, analyzed the experience of the role of managers in creating an innovative environment in an organization, analyzed positively and negatively influencing factors in the context of the management style and its role in creating conditions that affect implementation innovative potential, methods of a systematic approach, comparative analysis, synthesis, classification and periodization of the studied material.

Analyze: At the present stage, innovative thinking, despite its importance and relevance, remains for most people an obscure and underestimated phenomenon. But gradually managers and entrepreneurs come to understand that innovative thinking in the end result is profit, it is a lever for the development of any production, any business. According to M. Harper, only 4-5\% of people in the world have innovative thinking. Therefore, it is advisable to use this resource, thereby contributing to the further development of the country.

Innovative thinking is a skill that can be taught and that, with practical application, can be improved. It is important that all team members feel supported in the search, development and implementation of new ideas, and this will allow them to maximize their own innovative abilities and the overall potential of the organization as a whole.

As you know, managerial thinking can be effective or ineffective. In the event that it is implemented in the mode of outdated mechanical execution of routine procedures, cultivates bureaucratic laws, then results cannot be expected. On the other hand, managerial thinking can be 
extremely effective and in seemingly unpromising conditions to achieve exceptionally high results $[1 ; 8]$. Managerial thinking, as a phenomenon, is one of the most complex types of thinking and from the point of view of management psychology is a special type of human activity aimed at understanding the patterns of management processes, setting managerial problems and tasks, developing goals, principles, methods and ways of influencing objects management, building alternatives for solving problems, assessing and searching for resources. Such thinking includes basic (universal) and specific types of thinking, depending on the tasks and activities being solved $[1 ; 11]$.

Thinking is one of the most important human functions, the knowledge of which has been going on for centuries. There are many definitions of thinking. In philosophy, a science that studies the foundations of thinking and the development of a person's ideas about the world around him, thinking is defined as follows: "Thinking is the process of solving problems, expressed in the transition from the conditions that pose a problem to obtaining a result. Thinking involves active constructive activity on restructuring the initial data, their dismemberment, synthesizing and complementing", "Thinking is the ability of a person to connect images, ideas, concepts, determine the possibilities of their change and application, justify conclusions that regulate behavior, communication, further movement of thought itself ".

The basis of managerial thinking is formed by: dialectical thinking, which is based on the ability to reason, to reveal contradictions; analysis and synthesis; logical thinking, built on logical inferences, helping to distinguish true conclusions from false ones, assess the legitimacy and objectivity of the facts under consideration $[6 ; 20]$.

Thus, effective management thinking is a combination of logic, analysis and synthesis. In addition to the basic methods of thinking, there are more complex types of thinking. New types of thinking, studied and developed in recent decades, include such as innovative, managerial, strategic, critical, socially oriented managerial thinking, systemic - the highest level of thinking that synthesizes all types. Creative thinking in the work of a manager means that he can come up with new ideas and ways to solve problems, thereby realizing something innovative $[6 ; 24]$.

Managerial creative thinking is the ability to look at things in an innovative way that hasn't been previously seen. Creative thinking helps to invent or create something new: a concept, a solution to a problem, a technology, etc. In this regard, the role of creativity and creative thinking in the psychology of management is of great importance, since the requirements for managers are increasing, especially for such skills as the search and implementation of non-standard ideas in practice $[6 ; 24]$.

The innovative intelligence of a person is not just a manager's way of thinking, his nonstandard ideas, these are discoveries that were not invented and implemented at the previous stages of the organization's development.

The regularity of the relationship between the productivity of a person's innovative activity and his innovative intelligence was experimentally established. The productivity of an individual's (team's) innovative activity is simply the number of successfully completed tasks in an innovative environment.

In general, innovative activity can be considered as a complex process of creating, distributing and using a new practical tool [1;9]. Therefore, based on this definition, we can conclude that a person for successful innovative activity must develop his intellect in three directions: analytical, creative and practical.

Analytical intelligence is required to analyze the problem that has arisen, critically reflect on the existing approaches to overcome it. 
Creative intelligence, first of all, is necessary for generating productive ideas and searching for opportunities for their implementation based on solving problems of a divergent type.

Practical intelligence is required to use these ideas. With this understanding of the multiplicity of the nature of intelligence, which a person must possess to achieve success in innovation, a new construct is proposed innovative intelligence in the form of a model, the components of which are analytical, creative and practical intelligences. Practical intelligence lies in the ability to turn theory into practice, and abstract ideas into concrete results.

Practical intelligence is also needed in order to distinguish, among generally correct ideas, those that can be found for a specific application. A high level of ability to solve a task in a limited time is, of course, an integral part of practical intelligence [6;149].

As numerous studies show, people with even very high IQs do not always demonstrate success in life from a conventional point of view. For example, studies conducted at the University of California have shown that a person with a high IQ did not necessarily have the following qualities: independence and independence of thought and action, the ability to welcome complexity, originality, the ability to study the material comprehensively, flexibility and insight. However, it is these qualities that are necessary for fruitful innovation. Success in training and further professional activity necessarily presupposes, along with analytical development, the creative and practical qualities of a person.

A person who has only one creative component of intelligence, from among the many ideas put forward by him, is usually not able to select promising ones and exclude useless ones from consideration. Those with only analytical intelligence, as a rule, are brilliant critics of other people's ideas, but they themselves are not able to offer anything new and interesting. And, finally, if a person has a high level of practical intelligence alone, he can "sell" any idea he wants without presenting its true value $[6 ; 46]$.

Therefore, to achieve success in innovation, a balance of all three components of innovation intelligence is required.

In addition to all of the above, unique leadership qualities based on creative ideas and visions can help unite and unite the team, motivate it to work together to achieve the ultimate goal. Coordination of team activities is an important fundamental element of efficiency and requires a creative approach and the presence of a number of important personality traits, both employees and the manager [8; 628].

So, for example, if employees have the ability to think creatively, they can calmly perceive the emergence of innovations (as you know, people resist changes), moreover, they themselves often become a "generator of ideas" [3; 78].

It is necessary to note another important factor for the implementation of innovative transformations within the framework of practical activities. There is a natural relationship between leadership style and innovation. In organizations where excessive control is imposed (theory "X"), diktat, as described in the famous McGregor theory, there can be no innovation a priori, because creativity in such conditions is not realized. Managers in such organizations are focused on adhering to the rules that have already been worked out for years, social norms prescribing their strict, blind observance. Accordingly, such organizations lack an innovative environment, a creative atmosphere, and there is no place for innovation.

The view of the human and worker nature of a democratic leader differs from that of an authoritarian leader. MacGregor called them "Y" theory. He believed that the need for work is a natural need for a person. In his opinion, most of the employees are decent people who are 
responsible for their actions. If managers can create an enabling environment, workers will not only accept responsibility, but will also strive to improve their work. Many people have the ability to solve problems creatively, and the intellectual potential (in our understanding, innovative) is only partially used by the average worker [7, 98].

A truly democratic leader avoids imposing his decisions on subordinates, thereby contributing to an innovative environment, the realization of creative potential. As you know, organizations dominated by a democratic style are characterized by a high degree of decentralization of powers, and employees take an active, interested participation in decision-making, enjoy freedom in performing tasks. Quite often, by explaining the general task, the leader allows subordinates to define their goals in accordance with those that he formulated, thereby creating an innovative atmosphere. It is advisable to formulate three main recommendations for the development of an innovative environment that are of interest for practical application by organizations.

First, executives must provide value to their companies and therefore provide managerial support for creative thinking. This requires leaders to create a creative atmosphere, cultivate democratic and sometimes liberal leadership styles in certain conditions that promote the generation, selection and preservation of ideas, and not punish unsuccessful attempts.

Second, it is advisable to recruit employees taking into account the results of psychological testing (creativity tests), which determines the level of creativity of future employees (i.e., first of all, openness to experience, intrinsic motivation, divergent thinking and a cognitive style that promotes innovation, and not adaptation), taking into account not only the level of education, age indicators, etc.

Thirdly, it is important for managers to remember their invaluable role in the effective promotion of ideas and abilities, to create an environment in which ideas are born, developed, promoted and, most importantly, implemented, becoming a product, an innovation in their organization. It is also necessary to carry out a creative approach in personnel management, which will improve a good moral and psychological atmosphere and the quality of work performed.

To create an innovative environment, the top-priority task of managers is to involve employees in the creative process: conducting brainstorming, solving cases, conducting business games, etc. This interaction begins when a leader rethinks the meaning of employees in the company from a position of creative thinking. Rather than just passing directions, developing a top-down strategy, you need to involve people in the creative process so that employees understand the value of their contribution to the company.

Thus, the innovative thinking of the leader in all aspects: practical intelligence, analytical, directly creativity itself, in the development of the highest point gives a double result. Together with managerial abilities, they lead to the progress of the manager himself, in the organization - to the emergence of a new product, thereby bringing the company not only to a new level, but also to a leader.

\section{Conclusion:}

1. By developing his innovative intelligence, the leader should cultivate and maintain a creative atmosphere in his organization in which the exchange of ideas would be welcomed.

2. The method of trial and error, experimentation and development of innovative projects should be cultivated on standby from all employees and properly rewarded.

3. The manager, in addition to providing funds and resources for the implementation of the plan, must provide his subordinates with a certain freedom of action, since innovations cannot be carried out under the current rigid bureaucracy. 
4. For the formation and development of innovative thinking, employees must be trained in the skills of generating ideas, analyzing information, developing business projects.

5. A manager in any organization should create an innovative team, which should include creative people who are able to connect the theoretical and abstract aspects of technology with the commercial context of the organization.

6. It is advisable for managers to communicate to subordinates the information about how innovations can bring concrete results in order to inspire and increase the general interest in the new innovative initiative.

7. For effective implementation of innovations and, as a consequence, for further transformation of business processes in line with innovative development, changes are needed in all three areas: in corporate strategy and culture, in human resource management and in the company's business processes.

\section{Reference:}

1. Yanchevsky V.G. Innovation management. Concepts and categories - M.: Tetralit, 2018.144 p.

2. Godefroy J. What is psychology. Vol. 1. / per. with fr. N.N. Alipov - M.: Mir, 1992. 491 p. Ch. 9. Adaptation and creativity. Intelligence.

3. Change management. Textbook. - Moscow: Science, 2017. 869 p.

4. Safaryan K.V. Innovative business. - M.: Delo, 2016. $186 \mathrm{p}$.

5. Platonov V.V. Intellectual assets and innovation: problems of valuation, accounting and management. - Moscow, SPb.: Peter, 2019. 126 p.

6. Steinberg R. Practical intelligence. - SPb.: Peter, 2002.265 p.; (Masters of Psychology); ISBN 5318-00013-4.

7. Kartashova L.V., Nikonova T.V., Solomonidina T.O. Organizational behavior. - Moscow, Infra, $2001.220 \mathrm{p}$.

8. Dzhwell L. Industrial-organizational psychology. Ed. 4th. ZAO "Peter", 2001, 720 p. 